\title{
The Influence of Experienced Cattle on Grazing Behaviour of Calves in the Novel Pasture
}

\author{
Michiru FUKASAWA, Shusuke SATO, Aya NISHIWAKI and Kazuo SUGAWARA \\ Graduate School of Agricultural Science, Tohoku University, Aoba-ku, \\ Sendai-shi $981^{-8555, ~ J a p a n ~}$
}

(Received September 24, 1997 ; Accepted January 19, 1999)

\begin{abstract}
The objecting of this study was to examine and discuss how experienced cattle influence behaviour, especially grazing behaviour, of unexperienced calves. (1) In experiment 1,10 castrated calves and 2 cows were grazed in an artificial pasture for one month to familiarize and interact with each other. Then they were separated into 2 groups : one had 4 calves (M 1) with 2 cows and another had 6 calves only (C1). Two groups grazed separately on each native pasture with vegetation similar to each other. Grazing time, travelling speed and variety of grazed plants and drinking frequency of calves were compared. $\mathrm{C} 1$ behaved nervously only at the beginning of grazing : they moved more, grazed less and they drank more than M 1. Later calves in both groups behaved in the same way. (2) In experiment 2, 6 grazing unexperienced calves and 2 grazing experienced heifers were grouped into 2 : one consisted of 2 calves (M 2) with 2 heifers and another consisted of 4 calves only (C2). The 2 groups were each grazed on artificial pasture. Grazing time and rate of eating were compared between groups. Grazing time of $\mathrm{M} 2$ was significantly longer $(\mathrm{P}<0.05)$ than $\mathrm{C} 2$. Rate of eating in $\mathrm{M} 2$ was significantly higher $(\mathrm{P}<0.01)$ than in $\mathrm{C} 2$. It is thought that the existence of experienced cattle influences behaviour of calves under grazing situations.
\end{abstract}

Animal Science Journal 70 (2) : 74-80, 1999

Key words : Social learning, Experience, Grazing, Cattle

Recently, grazing has been reassessed from views of labor saving, efficient use of land and improvement of animal welfare. However, it has been indicated that there are some disadvantages of grazing in terms of production efficiency, such as climatic stress, instability of grass production, parasite infection, ingestion of plant poisoning. Growing calves are so influenced by those adverse conditions that their growth rates in pasture are lower than in shed, especially at the beginning of grazing. Therefore the technique of smoothly adapting calves to a new environment is very important for grazing management. Behavioural adaptation is more difficult than physiological and ruminal adaption ${ }^{14}$. At the beginning of grazing, the behaviour of calves is disturbed, because they are suffering from environmental stress and adapting to new surroundings and foods. They have to cope with en- vironmental impacts, adapt to their habitat, and become familiar with various edible plants.

Adaptation and learning are both influenced by social factors. Arnone and Dantzer ${ }^{13}$ reported that the presence of a companion appeared to moderate the impact of environmental stressors. The photographic images of their companion also suppressed isolation stress in sheep ${ }^{23)}$. Even the existence of a caretaker suppressed conflict stress and isolation stress ${ }^{21}$. Those results suggest that psychological stability is enhanced by the presence of a companion and that the companion plays an important role in suppressing environmental stress. In studies of gathering cattle by conditioned sound, Entsu ${ }^{4)}$ et al. showed that the existence of experienced cattle promoted the learning of unexperienced calves. In addition, social learning or imitative learning, a transfer of information from

Corresponding : Michiru FUKASAWA (fax : +81 (0) 22-717-8697, e-mail : fuka@bios.tohoku.ac.jp)

Anim. Sci. J. $70(2): 74-80,1999$ 
experienced animals to unexperienced, has been widely noticed on feeding behaviour. Many studies about social learning using sheep ${ }^{2,3,12,16,17,22)}$ suggested that lambs learned which foods were edible from social models which were experienced adults. In these studies, the best models were nurturant and peers $^{15)}$.

These results suggest the benefit of mixing adults which have abundant grazing experience with infant group which have no experience, even in cattle. The object of this study was to examine and discuss how experienced cattle influence behaviour, especially grazing behaviour of unexperienced calves.

\section{Materials and Methods}

Two experiments were conducted at the Tohoku University Farm, Naruko, Miyagi Pref., Japan. Subjects in experiments 1 and 2 were produced from a beef breeding herd and a dairy herd of the Tohoku Univ. Farm, respectively. Every year two herds were grazed from May to October and reared in a cattle shed afterward.

\section{Experiment 1}

The object of this experiment was to examine whether grazing behaviour and plants species ingested by castrated calves were different between with cows and without cows on native pastures. Calves were born in summer on mixed pasture (mainly consisted of artificial pasture) in the previous grazing season. Seven Japanese Black (JB) and 3 Japanese Shorthorn (JS) castrated calves and 2 Japanese Black cows which had experienced several grazing seasons were used. Before this experiment, all of them were exposed to artificial pasture with forest of Japanese cedar and pine trees for about a month to get to know each other and to interact. As there were very few edible native plants in this forest because of lack of sunshine and coldness in this pre-experimental period, the animals spent most of their time on an artificial pasture. The experiment took place from 25 June to 27 June 1996. Calves were separated into 2 groups at random. The group $\mathrm{M} 1$ consisting of $3 \mathrm{JB}$ and $1 \mathrm{JS}$ calves (Body Weight: 224-262 kg, Average Age : 11.8 months old) was grazed with 2 cows (BW : 455 and $435 \mathrm{~kg}, \mathrm{AA}: 49.5$ months old). The group C 1 consisting of $4 \mathrm{JB}$ and 2 JS calves (BW : 200-258 kg, AA : 11.5 months old) was grazed without cow.

$\mathrm{M} 1$ and $\mathrm{C} 1$ were each grazed on one of 2 native

Table 1. Relative appearance frequency and the number of species in both experimental pasture

\begin{tabular}{lcc} 
Group M 1 & & \\
\hline \hline & Frequency (\%) & No. of species \\
\hline Japanese pampas grass & 16.9 & 1 \\
Bushes and tree & 22.5 & 16 \\
Broad-leaved grass & 37.2 & 32 \\
Carex and Gramineae except & 8.0 & 7 \\
Japanese pampas grass & & \\
Pteridium & 15.4 & 3 \\
Group C1 & & \\
\hline & Frequency (\%) & No. of species \\
\hline Japanese pampas grass & 16.3 & 1 \\
Bushes and tree & 13.1 & 18 \\
Broad-leaved grass & 43.4 & 21 \\
Carex and Gramineae except & 12.1 & 6 \\
Japanese pampas grass & & 3 \\
Pteridium & 15.1 & \\
\hline
\end{tabular}


Table 2. Observation periods and their respective weather conditions on each day of investigation

(a) Experiment 1

\begin{tabular}{ccc}
\hline Day & Observation periods & Weather \\
\hline Day 1 & $12: 30 \sim 16: 30$ & Rainy, later cloudy \\
Day 2 & $5: 00 \sim 16: 30$ & Cloudy, occasional rainy \\
Day 3 & $5: 00 \sim 16: 30$ & Fair \\
\hline
\end{tabular}

(b) Experiment 2

\begin{tabular}{|c|c|c|c|c|}
\hline \multirow{2}{*}{\multicolumn{2}{|c|}{ Day }} & \multirow{2}{*}{ Observation periods } & \multicolumn{2}{|c|}{ Weather } \\
\hline & & & Group $\mathbf{M}$ & Group C \\
\hline Day 1 & & $13: 00 \sim 18: 00$ & Rainy & Fair \\
\hline \multirow[t]{2}{*}{ Day 2} & first & $4: 00 \sim 11: 00$ & Fair & Rainy \\
\hline & late & $11: 00 \sim 18: 00$ & Fair & Rainy \\
\hline \multirow[t]{2}{*}{ Day 3} & first & $4: 00 \sim 10: 00$ & Cloudy & Fair \\
\hline & late & $10: 00 \sim 16: 00$ & Rainy & Fair \\
\hline
\end{tabular}

pastures $(50 \mathrm{~m} \times 200 \mathrm{~m})$, respectively. Two experimental pastures were set up in broad slope with nograzing zone of $10 \mathrm{~m}$ distance between them. The no-grazing zone was dominated by bushes and trees so that the groups could not see each other and not influenced by each other's behaviour. Before grazing, plants were recorded every $4 \mathrm{~m}$ along five $200 \mathrm{~m}$ straight lines in each pasture. Numbers of plant species and frequency of each species were similar between the 2 pastures and the dominant plant species of both native pastures was Japanese pampas grass (Miscanthus sinensis) (Table 1). Observation period and weather of each day are shown in Table 2-a.

Grazing behaviour and ingested plants were investigated using a focal animal and instantaneous sampling method every $2 \mathrm{~min}$. The focal animal was changed every 20 min to check grazing behaviour of all calves. Each of M 1 with cows and C 1 moved as a group. The location of the group was plotted on 1/ 1,000 map every $10 \mathrm{~min}$ except the first observation day because of observational trouble. The travelling route on the map was measured using a digital curvimeter. Travelling distance/observation time was compared between groups. Drinking behaviour, being considered not only maintenance behaviour but also adjunctive behaviour, was determined by contin- uous sampling for all calves.

Five measurements as follows were compared between $\mathrm{M} 1$ and $\mathrm{C} 1$ by analysis of variance (GLM procedure : SAS Institute Inc., 1997) : (a) The time budget for grazing in observation time, (b) the number of drinking per hour, (c) the number of plant species ingested, (d) Simpson flexibility ${ }^{10)}$ of plant species ingested (as an index of variety of ingested plants), (e) the percentage of grazed Japanese pampas grass in the diet. Each data was pooled in each calf in each day. The effects of observation day, the group and their interaction were used as fixed effects. Measurements (a) and (e) were compared by parametric method and others by non-parametric method $^{18)}$.

\section{Experiment 2}

The objective of this experiment was to examine whether time spent grazing and the organic matter intake (OMI) rate of unexperienced calves were influenced by the existence of heifers having grazing experience on artificial pasture. Six Holstein calves with no grazing experience and 2 Holstein heifers with grazing experience on artificial pasture for over at least 2 months, were used. Calves were separated into 2 groups according to body weight. The group M 2 consisting of 2 calves (BW : 221 and $276 \mathrm{~kg}$, 
AA : 9.5 months old) was grazed with 2 heifers (BW : 522,481 kg, AA : 23.5 months old). The group C 2 consisted of only 4 calves (BW : 126-333 $\mathrm{kg}$, AA : 8.0 months old) was grazed without heifer. M 2 was pastured in a paddock of $2,200 \mathrm{~m}^{2}$ having standing crops of $201 \mathrm{~g} \mathrm{DM} / \mathrm{m}^{2}$. C 2 was pastured in a paddock of $1,980 \mathrm{~m}^{2}$ having standing crops of $188 \mathrm{~g}$ $\mathrm{DM} / \mathrm{m}^{2}$. The dominant species of both pastures was orchard grass. M 2 and $\mathrm{C} 2$ were investigated from 2 July to 4 July 1996 and from 5 July to 7 July 1996 , respectively. Observation periods and their respective weather conditions on each day of investigation are shown in Table 2-b.

The grazing behaviour of each calf was checked using scan sampling every $5 \mathrm{~min}$. The biting rate (no. of bites $/ \mathrm{min}$ ) of each calf was measured more than 5 times spanning over various grazing periods in order to estimate the organic matter intake (OMI) per minute by using Forbs' method ${ }^{6)}$.

The time budget for grazing and the OMI rate (mg $\mathrm{OMI} / \mathrm{min} / \mathrm{BW}^{0.75}$ ) throughout the entire observation time were compared between $\mathrm{M} 2$ and $\mathrm{C} 2$ by repeated measure analysis of variance (GLM procedure ; SAS Institute Inc., 1997). Data was taken repeatedly from both groups during the experimental period. The effects of the observational period and the group were used as fixed effects.

\section{Results and Discussion}

\section{Experiment 1}

At the beginning, the animals ran around the experimental pastures. After that, they started grazing, at which time they looked almost calm. Calves and cows in both group were more spread out in the native pasture than in the artificial pasture. Cows led M 1 and $\mathrm{M} 1$ moved and grazed more gregariously than $\mathrm{C}$ 1.

\section{The time budget for grazing}

On Day 1, M 1 started grazing about an hour after turned out, and finished grazing at the end point of observation. On the other hand, C 1 walked around while observing the new pasture more seriously. They started grazing in the later half of the observation period on Day 1. The effect on the time budget for grazing of group $\left(F_{1,24}=9.41, P<0.01\right)$, day
Table 3. The comparision of grazing time, drinking frequency and the variety of ingested plants between calves (M 1) with cows and calves alone (C1)

(a) The time budget for grazing (\%)

\begin{tabular}{cccc}
\hline \hline Group & Day 1 & Day 2 & Day 3 \\
\hline M 1 & $64 \pm 15.1^{\mathrm{a}}$ & $44 \pm 12.5^{\mathrm{b}}$ & $40 \pm 5.4^{\mathrm{bc}}$ \\
C 1 & $40 \pm 7.1^{\mathrm{b}}$ & $27 \pm 1.1^{\mathrm{c}}$ & $46 \pm 9.9^{\mathrm{b}}$ \\
\hline
\end{tabular}

(b) Drinking frequency/hour

\begin{tabular}{cccc}
\hline \hline Group & Day 1 & Day 2 & Day 3 \\
\hline M 1 & $0^{\mathrm{a}}$ & $0.11 \pm 0.03^{\mathrm{b}}$ & $0.04 \pm 0.02^{\mathrm{c}}$ \\
C 1 & $0^{\mathrm{a}}$ & $0.20 \pm 0.05^{b}$ & $0.20 \pm 0.05^{\mathrm{bc}}$
\end{tabular}

(c) The number of ingested plant species

\begin{tabular}{cccc}
\hline Group & Day 1 & Day 2 & Day 3 \\
\hline M 1 & $6.3 \pm 0.4^{\mathrm{ab}}$ & $11.0 \pm 1.1^{\mathrm{c}}$ & $8.0 \pm 1.9^{\mathrm{ac}}$ \\
C1 & $5.0 \pm 0.5^{\mathrm{a}}$ & $8.7 \pm 1.2^{\mathrm{bc}}$ & $8.7 \pm 0.6^{\mathrm{c}}$
\end{tabular}

(d) Simpson flexibility of ingested plant species

\begin{tabular}{cccc}
\hline \hline Group & Day 1 & Day 2 & Day 3 \\
\hline M 1 & $3.5 \pm 0.3$ & $5.1 \pm 1.1$ & $5.5 \pm 1.4$ \\
C1 & $4.3 \pm 0.6$ & $5.0 \pm 0.8$ & $5.5 \pm 0.6$
\end{tabular}

(e) The percentage of Japanese pampus grass in the diet $(\%)$

\begin{tabular}{cccc}
\hline \hline Group & Day 1 & Day 2 & Day 3 \\
\hline M 1 & $33.3 \pm 7.6$ & $34.8 \pm 10.7$ & $29.5 \pm 4.0$ \\
C 1 & $18.9 \pm 4.8$ & $31.8 \pm 6.8$ & $32.8 \pm 3.3$ \\
\hline
\end{tabular}

$\overline{a, b, c}$ Different superscripts in each table represent significant difference $(\mathrm{P}<0.05)$.

Each value represents mean \pm standard deviation.

$\left(F_{2,24}=6.20, P<0.01\right)$ and their interaction $\left(F_{2,24}-\right.$ $5.84, \quad \mathrm{P}<0.01$ ) were significant (Table 3-a). On Days 1 and 2, the time budget for grazing were significantly longer in $\mathbf{M} 1$ than in $\mathrm{C} 1$.

\section{Travelling speed}

At the beginning, the cows and calves ran around this experimental pasture. They began to walk in a usual pace ${ }^{7)}$ during Day 2, when $\mathrm{M} 1$ and $\mathrm{C} 1$ walked $2.6 \mathrm{~m} / \mathrm{min}$ and $2.4 \mathrm{~m} / \mathrm{min}$, respectively. On Day 3 , $\mathrm{M} 1$ and $\mathrm{C} 1$ walked $0.9 \mathrm{~m} / \mathrm{min}$ and $1.3 \mathrm{~m} / \mathrm{min}$ respectively. There was no difference between groups on each day. 


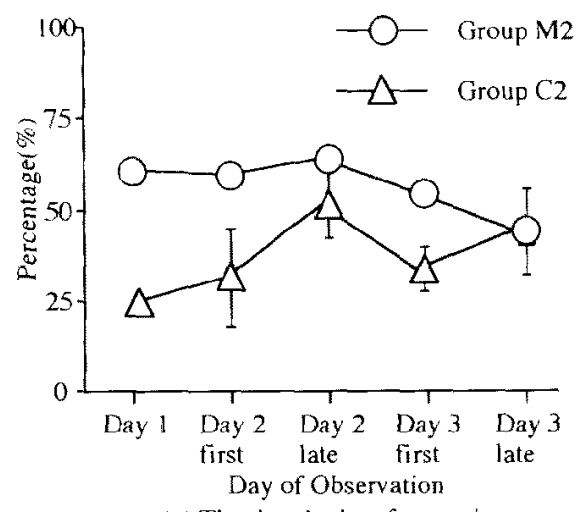

(a) The time budget for grazing

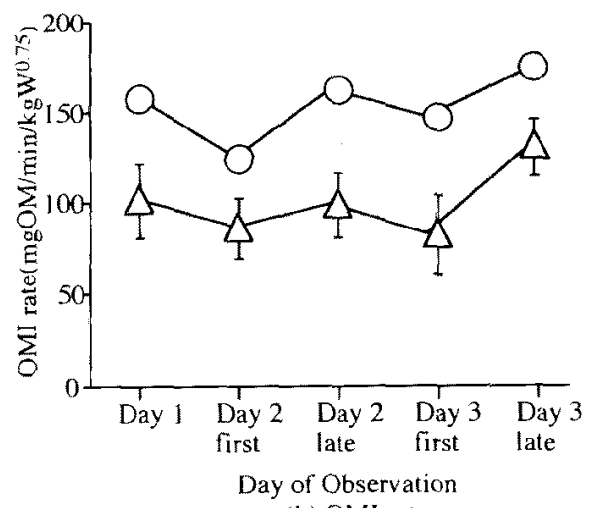

(b) OMI rate

Fig. 1. The time budget for grazing and OMI rate in group M2 $(O)$ and in group $\mathrm{C} 2(\triangle)$ in Experiment 2.

Each symbol represents mean \pm standard deviation.

\section{Drinking}

The effects on drinking frequency of group $\left(F_{1,24}=\right.$ $4.39, \mathrm{P}<0.05)$ and day $\left(\mathrm{F}_{2,24}=22.71, \mathrm{P}<0.01\right)$ were significant (Table 3-b). C 1 drank more frequently than M 1. Falk ${ }^{5}$ suggested that obstruction of intake brought out adjunctive behaviour. Adjunctive behaviour occurs when animals are under mental conflicts or frustration. Commonly, adjunctive behaviour is excessive grooming or drinking behaviours. It is said ${ }^{21)}$ that adjunctive behaviour has a calming effect for the agitation caused by mental conflicts or frustration. In this experiment, the sudden change of grazing environment might be an obstruction of their usual grazing behaviour and had the effect of accelerated drinking, which was thought of as an adjunctive behaviour. It is suggested that calves with cows might be psychologically more stable than without cows.

\section{Ingested plant}

Tables 3-c, d, e show that there were no significant differences between groups. Both groups grazed Japanese pampas grass more selectively than the other species of vegetation.

In experiment 1, the existence of cows hardly influenced the grazing behaviour of calves except at the beginning of native pasture grazing. It is said that selection of edible food and preference are seriously affected by experience before weaning ${ }^{12)}$. In this experiment, calves were born in the previous summer and had experienced grazing in the mixed pasture (mainly consisted of artificial pasture) before weaning. In addition, calves had experienced another grazing season in the pre-experiment.

At the beginning of grazing, the behaviour was more disturbed in C 1 than in M 1 . C 1 moved more and grazed less. As empirically known, many incidents (e.g. escape from pasture) occur just after the start of grazing. The disturbance of behaviour, even if slight, should be paid attention from the view of bchavioural management.

\section{Experiment 2}

\section{Time budget for grazing}

Figure 1-a shows that M 2 grazed longer than C2 $\left(F_{1,4}=15.14, \mathrm{P}<0.05\right)$. Hafez ${ }^{7)}$ reviewed that grazing time was $4-9$ hours per a day $(17 \%-38 \%)$. Considering cattle scarcely graze at night, it is thought that time budget for grazing in M 2 was at normal level, and in $\mathrm{C} 2$ was at a slightly low level.

\section{OMI rate}

Fig 1-b shows that $\mathrm{M} 2$ ingested organic matter more quickly than $\mathrm{C} 2\left(\mathrm{~F}_{1,4}=21.28, \mathrm{P}<0.01\right)$. This might be attributed to the difference in a rate of biting between groups. Kobayashi et al. ${ }^{11)}$ suggested that calves having no grazing experience have poor grazing technique and our result agreed with this. OMI rate differed between groups even in the last day, so it is needed to ascertain how long the effect of cohabitation with heifers lasts.

Ishii ${ }^{9)}$ reported that young cattle could learn "right grazing behaviour" and then they could gain higher 
body weight. "Right" means an adaptive grazing pattern (e.g. when and where they start grazing and how long to spend) and the skills of efficient grazing.

Diffusion of grazing behaviour by social imitation was reported on many animals ${ }^{13)}$. Experience through imitation may lead to more efficient learning than trial and error. In experiment 2, it was suggested that imitation leads more to efficient grazing even in cattle.

Experiment 1 revealed that calves without cows were more psychologically disturbed than with cows, at the beginning of grazing. Experiment 2 revealed that grazing behaviour of unexperienced calves without heifer was less effective than with heifers. As previously suggested, we think that the different effect of experienced cattle on the calves' behaviour mainly derived from various previous experiences (feeding, handling, etc.) of the experimental calves.

In addition, the following factors may also be responsible :

(1) Breed : Sato et al. ${ }^{19)}$ showed that castrated Holstein calves behaved more cohesively than JBs and JSs. It may be thought that Holstein cattle are easily affected by companionship.

(2) Geographic features: Geographic features were more complex in the paddock of experiment 1 than experiment 2. Native pasture used in experiment 1 consisted of ridges and slopes. Artificial pasture of experiment 2 was plain and simple. Hayashi ${ }^{8}$ reported that the more complex geographic features were, the more spread out cattle were, and that cattle gathered on plain artificial pasture. It may be thought that cattle are easily affected by their companions on plain pastures.

(3) Age difference between calves and experienced cattle : Age difference was 3 years in experiment 1 and 1 year in the experiment 2 . Social learning studies revealed ${ }^{15}$ that the best models were nurturant and peers. Psychological intimacy may be effective for social learning. Sato et al. ${ }^{20)}$ showed that intimate relationships were made more easily among cattle when their age difference was within a year. In this case, heifers in experiment 2 might be effective as a social model.

Anim. Sci. J. 70 (2) : 74-80, 1999
It is concluded that the existence of experienced cattle influenced behaviour of calves due to psychological stability and imitation. It may be possible to reduce the stress of calves by rearing them with cows just after the start of grazing when many grazing incidents occur. We need to examine how soon calves can adapt to new environments under the existence of experienced cattle and how long these changes will be kept, even if calves are separated from them. It is also needed to examine how this difference affects the productivity of calves, especially growth on a long span view.

\section{Reference}

1) Arnone M, Dantzer R. Does frustration induce aggression in pigs? Applied Animal Ethology, $6: 351-$ 362. 1980.

2) Chapple RS, Wodzicka-Tomaszewska M. The learning behaviour of sheep when introduced to wheat. II. wheat acceptance by sheep and the effects of trough familiarity. Applied Animal Behaviour Science, 18 157-162. 1987.

3) Chapple RS, Wodzicka-Tomaszewska M, Lynch JJ. The learning behaviour of sheep when introduced to wheat. I. social transmission of wheat feeding and the role of sense. Applied Animal Behaviour Science, 18 : 163-172. 1987.

4) Entsu S, Ando F, Morozumi K. Control of behaivor of young cattle under restricted grazing with night kraaling. III improvement of method for tending cattle by condition sound. Bulletin of National Grassland Research Institute, $16: 128-142.1980$.

5) Falk JL. Theorical review. The nature and determinants of adjunctive behavior. Physiology and Behaviour, $6: 577-588.1971$.

6) Forbs TDA. Researching the plant-animal interface : The investigation of ingestive behaviour in grazing animals. Journal of Animal Science, $66: 2369-2379$. 1985.

7) Harfez ESE, Bouissou MF. The behaviour of cattle. In : The Behavior of Domestic Animals. (Harfez ESE ed.) 203-245. Baillere Tindall. London. 1975.

8) Hayashi K. Bionomics of grazing animal. In : Encyclopedia of Animal Production (Naito M. ed.) 685696. Yoken-do. Tokyo. 1978. (In Japanese)

9) Ishii T. Guide to Ethology of Cattle. 17 38. Central Association of Livestock Industry. Tokyo. 1986. (In Japanese) 


\section{FUKASAWA, SATO, NISHIWAKI and SUGAWARA}

10) Ito S, Miyata I. Flexibility of species in a community, In : Constitution and Structure of Community. (Ito S ed.) 83-90. Asakura-shoten. Tokyo. 1977. (In Japanese)

11) Kobayashi H, Tahata I, Ami $T$, Oshio S, Iso M, Igarashi R, Fukukawa T, Takahashi S. Effects of experience on pasture on grazing performance. Bulletin of National Grassland Research Institute, 6 : 105110. 1975. (In Japanese with English abstract)

12) Lobato JFP, Pearce GR, Beilharz RG. Effects of early familiarization with dietary supplements on the subsequent ingestion of molasses-urea blocks by sheep. Applied Animal Ethology, 6: 149-161. 1980.

13) Michael D. Imitation. In : The Oxford Dictionary of Animal Behavior. (McFarland D ed.) 716-722. Doubutsu-sha. Tokyo. 1993. (In Japanese ; translated by Kimura $\mathrm{T}$ )

14) Oshio S, Tahata I. Studies on the method of adaptation to grazing environment. II. influence of various feeds before grazing on the microbial populations in the rumen of calves grazed on pasture. Bulletin of National Glassland Research Institute, 20: 132-144. 1981. (In Japanese with English abstract)

15) Provenza FD, Balpph DF. Diet learning by domestic ruminants : theory, evidence, and practical implications. Applied Animal Behaviour Science, 18 : 211232. 1987.

16) Sarwat NM, Provenza FD. Preference of the mother affects selection and avoidance of foods by lambs differing in age. Applied Animal Behaviour Science, $28: 255-263.1990$.

17) Sarwat NM, Provenza FD. Effects of age and conditions of exposure on maternally mediated food selec tion by lambs. Applied Animal Behaviour Science, $33: 35-42.1992$.

18) SAS/STAT Software User's Guide : Version 6, first ed. SAS inst. Inc, Cary. NC. 1995.

19) Sato S, Yamagishi T, Mizuma Y. Studies on separation and integration of grazing cattle. Journal of Japan Grassland Science, 22 : 307-312. 1976. (In Japancse with English abstract)

20) Sato $S$, Sassa H, Sonoda $T$. Effects of the dominance rank of partner cows on social behavior of newly introduced heifers. Japan Journal of Livestock Management, $26: 64-69$. 1990. (In Japanese with English abstract)

21) Sato S. Distributed behaviour and animal welfare. In : Farm Animal Behavior. 2nd ed. (Mimura K ed.) 98-121. Yoken-do. Tokyo. 1997. (In Japanese)

22) Thorhallsdottir AG, Provenza FD, Balph DF. Ability of lambs to learn about novel foods while observing or participating with social models. Applied Animal Behaviour Science, 25 : 25-33, 1990.

23) Vandenheede M, Bouissou MF. Fear reactions of ewes to photographic images. Behavioural Processes, $32: 17-28.1994$ 